\title{
Carbenoxolone sodium in the treatment of gastric ulcer with special reference to side-effects
}

\author{
A. G. G. TURPIE AND T. J. THOMSON \\ From the Gastrointestinal Unit, Stobhill General Hospital, \\ and Western District Hospital, Glasgow
}

EDITORIAL SYNOPSIS This paper indicates the need for close clinical and biochemical observation of the patient during treatment with carbenoxolone.

In 1962, Doll, Hill, Hutton, and Underwood reported the results of a clinical trial of a triterpenoid liquorice compound, carbenoxolone sodium (Biogastrone), in the treatment of gastric and duodenal ulcer. They suggested that carbenoxolone sodium promotes the healing of gastric ulcers. The results in patients with duodenal ulcer were not significantly different from those receiving placebo tablets. Of 58 patients who were given the active drug in a dose of $100 \mathrm{mg}$. three times daily for four weeks, $10(17 \%)$ developed oedema. In 1965, Doll, Hill, and Hutton, in a further series, re-affirmed the value of carbenoxolone sodium in promoting the reduction in size of gastric ulcers. Twenty-four patients were treated as out-patients using doses of 75 to $100 \mathrm{mg}$. three times daily of carbenoxolone sodium. In this series, a liability to fluid retention was again noted: $21 \%$ of patients developed oedema of the ankles and showed a rapid gain in weight. During the later stages of the second trial the blood pressure was recorded weekly and in a number of patients significant elevation of the systolic and diastolic blood pressure was noted. The mean maximum increase of pressure over the pretreatment reading was $20 \mathrm{~mm}$.Hg systolic and $12 \mathrm{~mm} . \mathrm{Hg}$ diastolic for the carbenoxolone sodium group. In one patient the increase in diastolic pressure was $30 \mathrm{~mm} . \mathrm{Hg}$.

This communication describes our experience using carbenoxolone sodium in doses of $100 \mathrm{mg}$. three times daily and $50 \mathrm{mg}$. three times daily in the treatment of patients with gastric ulcer. Special attention was paid to the incidence of side-effects.

\section{METHOD}

A double-blind pilot trial of carbenoxolone sodium was carried out in 12 patients with gastric ulcer. Only patients in whom the profile of the gastric ulcer niche was greater than 10 sq.mm. in area (Doll et al., 1962) were included in the trial. Six patients received the active drug in a dose of $100 \mathrm{mg}$. three times daily and six received inert placebo tablets. A further four patients were given carbenoxolone sodium in a dose of $100 \mathrm{mg}$. three times daily. All subjects were in-patients and the drug therapy was given for a maximum period of one month. Patients were allowed up to go to the lavatory, took a light ward diet, and were encouraged to take freely milk and antacid (colloidal aluminium hydroxide) whenever dyspeptic symptoms occurred. They were advised to stop smoking cigarettes. Progress was recorded at weekly intervals, by full clinical examination, by barium meal examination, and in many by fibroscopy. Also at weekly intervals serum electrolytes and urea were measured; liver function tests were carried out and routine blood examinations were made (haemoglobin, packed cell volume, and white blood count). There were weekly electrocardiograms and chemical analyses of the urine. The weight was recorded at least once weekly, and more frequently if indicated. The blood pressure was recorded at least twice weekly and in some cases daily. In the double-blind trial, two patients, one from each group, left hospital after two weeks and did not return for follow-up examination.

\section{RESULTS AFTER FULL DOSES OF CARBENOXOLONE}

Clinical assessment of dyspepsia showed no difference between the groups, as almost all symptoms subsided within a few days of admission to hospital. The rate of healing of ulcers, as judged by barium meal $x$-ray examination, is detailed in Table $I$. Although the small number of patients does not permit a firm conclusion to be drawn, there appeared to be, after four weeks, and more strikingly at two weeks, a greater degree of healing in those patients who had received the active drug.

Liver function tests (serum bilirubin, thymol turbidity, alkaline phosphatase, serum albumin and serum globulin) remained normal during the period of treatment. The blood urea was not significantly altered. Routine urine analysis showed no abnormality. The levels of serum sodium showed some 
TABLE I

REDUCTION IN SIZE OF GASTRIC ULCER CRATER AFTER TWO AND FOUR WEEKS' TREATMENT WITH CARBENOXOLONE SODIUM (SIX PATIENTS) AND PLACEBO (SIX PATIENTS)

\begin{tabular}{|c|c|c|c|c|}
\hline \multirow{2}{*}{$\begin{array}{l}\text { Patient } \\
\text { No. }\end{array}$} & \multirow[t]{2}{*}{ Treatment } & \multicolumn{3}{|c|}{ Profile Size of Crater (sq.mm.) } \\
\hline & & Pretreatment & Two Weeks & Four Weeks \\
\hline 2 & $\begin{array}{l}\text { Carbenoxolone } \\
\text { (100 mg. t.i.d.) }\end{array}$ & 45 & $\mathbf{0}$ & \\
\hline 3 & $\begin{array}{l}\text { Carbenoxolone } \\
\text { (100 mg. t.i.d.) }\end{array}$ & 221 & 47 & $\mathbf{0}$ \\
\hline 6 & $\begin{array}{l}\text { Carbenoxolone } \\
\text { (100 mg. t.i.d.) }\end{array}$ & 27 & 0 & \\
\hline 8 & $\begin{array}{l}\text { Carbenoxolone } \\
\text { (100 mg. t.i.d.) }\end{array}$ & 30 & $\mathbf{0}$ & \\
\hline 9 & $\begin{array}{l}\text { Carbenoxolone } \\
\text { (100 mg. t.i.d.) }\end{array}$ & 23 & 10 & $\mathbf{0}$ \\
\hline 12 & $\begin{array}{l}\text { Carbenoxolone } \\
\text { (100 mg. t.i.d.) }\end{array}$ & 13 & 6 & $\begin{array}{l}\text { No } \\
\text { radiograph }\end{array}$ \\
\hline 1 & Placebo & 47 & 14 & 13 \\
\hline 4 & Placebo & 104 & 42 & 28 \\
\hline 5 & Placebo & 281 & 280 & $\begin{array}{l}\text { No } \\
\text { radiograph }\end{array}$ \\
\hline 7 & Placebo & 13 & 0 & \\
\hline 10 & Placebo & 46 & 26 & $\mathbf{0}$ \\
\hline 11 & Placebo & 18 & 0 & \\
\hline
\end{tabular}

increase, but not beyond normal limits. Haematological assessment showed no abnormality: especially there was no significant alteration in the packed cell volume.

SIDE-EFFECTS Two patients receiving carbenoxolone had disturbing but transient retrosternal pain without electrocardiographic changes. Three patients (two receiving active drug and one the inert) complained of headache. Heartburn was complained of by patients in both groups. Three patients in the carbenoxolone group developed oedema and their weights increased respectively by $5.1 \mathrm{~kg}$., $5.9 \mathrm{~kg}$., and $2.2 \mathrm{~kg}$. A striking difference in blood pressure was found in the carbenoxolone group and the placebo group. In five of the 10 patients who were given carbenoxolone sodium, increase in the diastolic blood pressure of over $20 \mathrm{~mm}$. Hg was noted. In two patients, diastolic levels exceeding $120 \mathrm{~mm} . \mathrm{Hg}$ were recorded; the pretreatment readings had been $80 \mathrm{~mm} . \mathrm{Hg}$. The drug was discontinued and in both instances the blood pressure returned to normal. Oedema and elevation of blood pressure responded to diuretic therapy; this was required in three patients. A brisk diuresis followed the administration of spironolactone in one patient. The others were given bendrofluazide.

The level of serum potassium fell in the majority of patients receiving carbenoxolone sodium. In four of the 10 patients the levels fell below $3.0 \mathrm{mEq} . / 1$. In one patient the fall in serum potassium occurred after the administration of the diuretic bendrofluazide in a dose of $5 \mathrm{mg}$. daily, although this was combined with an oral supplement of potassium chloride in a dose of $1 \mathrm{~g}$. daily. The level remained low despite the administration of supplementary potassium in a dose of $4 \mathrm{~g}$. daily. In two patients the electrocardiogram showed changes consistent with hypokalaemia; prominent $U$ waves were noted and $T$ waves became flat, but these changes were transient.

Thus with the administration of carbenoxolone sodium to 10 patients in a dose of $100 \mathrm{mg}$. three times daily significant signs of toxicity were recorded: there was an increase in blood pressure in five, oedema in three, and hypokalaemia in four.

We therefore studied the action of carbenoxolone sodium in a further group of 10 patients with gastric ulcer but on this occasion the dose was reduced to $50 \mathrm{mg}$. three times daily. The patients were selected and treated by the methods described above; and they were assessed at weekly intervals. Although the number of patients is small, the results on $x$-ray examination after four weeks are interesting (Table II). It will be seen that in six of the 10 patients the ulcer was 'healed' on $x$-ray examination. The average reduction in size of ulcer in the 10 cases was $81 \%$. Table III compares the reduction in size of the ulcer in the three groups of patients treated.

\section{TABLE II}

REDUCTION IN SIZE OF GASTRIC ULCER CRATER AFTER TREATMENT WITH CARBENOXOLONE SODIUM IN A DOSE OF $50 \mathrm{mg}$. THREE TIMES DAILY

Profile Size of Ulcer (sq.mm.)

\begin{tabular}{ccc}
\hline Pretreatment & Four Weeks & $\%$ Reduction \\
\hline 20 & 0 & 100 \\
430 & 210 & 51 \\
20 & 0 & 100 \\
22 & 22 & 0 \\
38 & 0 & 100 \\
70 & 0 & 100 \\
108 & 0 & 100 \\
46 & 12 & 74 \\
26 & 0 & 100 \\
110 & 19 & 83 \\
& & Average 81
\end{tabular}

TABLE III

RESULTS OF TREATMENT OF GASTRIC ULCER ASSESSED BY CHANGE IN SIZE OF ULCER

Dose of Biogastrone Three Average Reduction in Size of Times Daily $\quad$ Ulcer (\%)

\begin{tabular}{lcc} 
& At Two Weeks & At Four Weeks \\
\hline 100 mg. (6) & & \\
50 mg. (10) & $82(6)$ & $100(5)$ \\
Inert tablet (6) & $-63(6)$ & $81(10)$ \\
& & $89(5)$
\end{tabular}

${ }^{1}$ No. of patients

SIDE-EFFECTS FOLLOWING SMALL DOSES OF CARBENOXOLONE Using a dose of $50 \mathrm{mg}$. three times daily the weight increased by more than $3 \mathrm{~kg}$. in four 
patients, although only two of them developed clinical oedema; this rapidly cleared with diuretic therapy. The other side-effects were related to the blood pressure and the level of serum potassium. In three out of the 10 patients the systolic pressure rose by more than $20 \mathrm{~mm} . \mathrm{Hg}$, and in two the diastolic pressure increased by more than $20 \mathrm{~mm} . \mathrm{Hg}$. In one of these, a man aged 55 years, the resting level of $140 / 70$ rose within 10 days to $188 / 100$ and there was accompanying severe headache. Treatment with the drug was therefore discontinued. The level of serum potassium fell to below $3.5 \mathrm{mEq}$./l.in three patients $(3.4,3.0,2.7 \mathrm{mEq} . / \mathrm{l}$.). There was no significant alteration in the liver function tests, levels of serum urea, sodium and chloride. Examination of blood and urine revealed no abnormalities.

In summary, administration of carbenoxolone sodium in a dose of $50 \mathrm{mg}$. three times daily to 10 patients was followed by increase in weight in four, diastolic hypertension in two, and hypokalaemia in three.

\section{DISCUSSION}

The purpose of this study was to record the sideeffects occurring in 20 patients in hospital receiving carbenoxolone sodium over a period of four weeks. In 10 the dose was $100 \mathrm{mg}$. three times daily and in the remainder $50 \mathrm{mg}$. three times daily.

The most striking side-effects were gain in weight, hypertension, and hypokalaemia. Borst, ten Holt, de Vries, and Molhuysen (1953) and Salassa, Mattox, and Rosevear (1962) have shown that extracts of liquorice produce retention of sodium and water and excretion of potassium in man. Doll and his colleagues (1965) found that $21 \%$ of their patients receiving carbenoxolone sodium developed oedema of the ankles, and one patient became dyspnoeic and slightly oedematous during the first week of treatment. We found that three out of 10 patients on a dose of carbenoxolone sodium of $100 \mathrm{mg}$. three times daily and two of 10 patients receiving $50 \mathrm{mg}$. three times daily developed oedema. It is clear that even the smaller dose can give rise to this undesirable side-effect and may aggravate the tendency to retention of fluid in patients with cardiac or renal disease.

Hypertension was a common side-effect in patients receiving this drug. Using a rise of more than $20 \mathrm{~mm}$. of mercury in the level of diastolic pressure as being significant, we found that five of the 10 patients on $300 \mathrm{mg}$. daily and two of the 10 patients on $150 \mathrm{mg}$. daily developed hypertension. In one of the patients on the smaller dose (a man aged 55 years), a rise in the diastolic pressure of $\mathbf{4 0} \mathrm{mm} . \mathrm{Hg}$ occurred within 10 days of his starting treatment; the drug had to be withdrawn. We consider that such a rapid rise in blood pressure is not without hazard and constitutes a serious handicap to the widespread use of carbenoxolone sodium.

Hypokalaemia developing during treatment with carbenoxolone sodium presents a special problem; it may pass unnoticed until dangerously low levels of serum potassium occur. Only by repeated estimations of the level of serum potassium at short intervals can this hazard be detected, and biochemical supervision of this kind is rarely available except in hospital practice. The use of carbenoxolone sodium for the treatment of gastric ulcer in out-patients has been inferred by Doll et al. (1965) who state that: 'carbenoxolone sodium ... accelerates healing, which can be achieved with patients remaining up and about, often at work, and with minimum change in diet'. Taking $3.5 \mathrm{mEq}$./l. as the lower normal limit of serum potassium, hypokalaemia occurred in the present series in seven out of 20 patients $(35 \%)$; in four, the dose of carbenoxolone sodium was $100 \mathrm{mg}$. three times daily, and in three the dose was $50 \mathrm{mg}$. three times daily. Tárnoky and Hausmann (1964), quoted by Doll et al. (1965), found hypokalaemia and hypertension after two weeks' treatment with carbenoxolone sodium. It has been recommended that a thiazide diuretic should be given if the patient's weight increases or oedema develops. The known tendency of the benzothiadiazine diuretics to increase urinary excretion of potassium could also increase the danger of hypokalaemia. It may be that spironolactone is the diuretic of choice in patients who develop oedema on administration of carbenoxolone sodium (Salassa et al., 1962).

Such observations emphasize the difficulty of controlling the safe use of carbenoxolone sodium in domestic practice. It is essential that a close check be kept on the patient's weight, the occurrence of oedema, and the onset of hypertension and hypokalaemia. In effect this means that the use of carbenoxolone sodium should be restricted to hospital patients. It is true that the incidence of side-effects with a dose of $150 \mathrm{mg}$. daily of carbenoxolone sodium appears to be less (though by no means negligible) than it is with $300 \mathrm{mg}$. daily, but there is as yet no evidence that these small doses of carbenoxolone have therapeutic effects in patients suffering from gastric ulcer.

\section{SUMMARY}

In a pilot trial the effects of carbenoxolone sodium on the healing of gastric ulcer have been compared with those of placebo tablets. Observations were carried out on 12 patients and the double-blind technique was used. The dose of carbenoxolone was 
$300 \mathrm{mg}$. daily $(100 \mathrm{mg} . \times 3)$. A further four patients with gastric ulcer were given the same dose.

Another group of 10 patients with gastric ulcer received $150 \mathrm{mg}$. of carbenoxolone sodium daily $(50 \mathrm{mg} . \times 3)$. All were hospital in-patients and the courses of treatment ran for four weeks. Special attention was paid to the occurrence of possible side-effects.

In a small series of patients receiving carbenoxolone, side-effects were frequent and troublesome. In the 10 patients who received $100 \mathrm{mg}$. three times daily, oedema developed in three, hypertension in five, and hypokalaemia in four. When a further 10 patients were given $50 \mathrm{mg}$. three times daily, oedema developed in two, hypertension in two, and hypokalaemia in three.

The need for close clinical supervision and frequent measurement of serum potassium level is stressed. It is concluded that carbenoxolone sodium should be used only when biochemical assessment of the patient can be carried out.

We are grateful to Professor S. Alstead for his guidance and encouragement, and to Biorex Laboratories for supplies of carbenoxolone sodium and inert tablets.

\section{REFERENCES}

Borst, J. G. G., Holt, S. P. ten, Vries, L. A. de, and Molhuysen, J. A. (1953). Synergistic action of liquorice and cortisone in Addison's and Simmond's disease. Lancet, 1, 657-663.

Doll, R., Hill, I. D., and Hutton, C. F. (1965). Treatment of gastric ulcer with carbenoxolone sodium and oestrogens. Gut, 6, 19-24.

,,-- and Underwood, D. J., II (1962). Clinical trial of a triterpenoid liquorice compound in gastric and duodenal ulcer. Lancet, 2, 793-796.

Salassa, R. M., Mattox, V. R., and Rosevear, J. W. (1962). Inhibition of the 'mineralocorticoid' activity of licorice by spironolactone. J. clin. Endocr., 22, 1156-1159.

Tárnoky, A. L., and Hausmann, W. (1964). Quoted by Doll, R., Hill, I. D., and Hutton, C. F. (1965). Gut, 6, 19-24. 